\title{
Application and Development at Home of Geographical Information System in Forestry Resource
}

\author{
Jing Zeng ${ }^{1,}$, , Jianjun Liao*,b \\ ${ }^{1,2}$ Urban Construction Institute, University of South China, Hengyang, Hunan, 421001 \\ a,b375458672@qq.com
}

\begin{abstract}
Keywords: Geographical Information System(GIS); Forestry Resource; Application Study Abstract. Geographic Information System (GIS) is a comprehensive spatial data processing technique, of which fundamental meaning, function, background and developing process are introduced in the paper. It is reviewed and emphasized that GIS has been applied to forestry industry fully and systematically in recent years as following: information management, operating optimized decision, classified management division, sample design, thematic mapping, cutting plan, afforestation planning programming, protection, resource administration net GIS, precision forestry. Also the further study and development are discussed finally
\end{abstract}

\section{Introduction}

Geographic Information System(GIS) is a comprehensive spatial data processing technique, which was coming into being in 1960s of the early 20 century, and has got rapid development as a research focus at home and abroad in recent years with the development of computer, space, as well as radio transmission technology and so on [1]. With long-term growth, vast regionalism distribution, reproduction, and uncertainty maturity of forestry resource, the information has following characteristics: one is regional distribution, which shows distributed region and multilevel property; one is scale data with both spatial orientation and attributive character as survey factors; one is diverse, i.e. poly-phase survey data, in time dimension because the growth of forests changes over time; one is diversity of semantide, such as characters, numbers, figures, stock maps, images, papers, tapes, compact disks, etc. It has exposed serious disadvantages that using traditional methods to manage and express resource information of forestry and guide forestry production. Therefore, it becomes a trend to adopt new techniques, such as GIS, to make forestry operating management in a specific area digitization, integration, intelligent and networked, in order to offer a technological support for sustainable development and a new management approach for modernization of forestry [2].

\section{Basic Meanings and Development Profiles}

So far there is no uniform definition for GIS, that is to say that scholars have different understanding in different subjects and fields. Some thinks that GIS is a computer system to collect, store, manage, analyze, show, and apply geographic information, and a general technique to deal with massive geographic data, which is made up of computer hardware, software, geographic spatial databases and managers [3]. As a high-level comprehensive management technique, its advantages are data fusing, geographic modeling and spatial analysis capacity.

GIS can be regard as a inevitable outcome that information technology develops into certain stage, of which widespread application can play an important role in resource and environment, and has being widely used in resource administration, urban and regional planning and military fields [4]. As early as 1960s, Doctor Roger F. Tomlinson from Canada put forward making maps digitization as to process and analyze conveniently using computer. And then Garison W. L. Coined the term "GIS". GIS was invented and used at the earliest internationally, the main purpose of which was to process a mountain of land investigation data. In 1970s, with rapid development of computer, which provided powerful means for input, storage, and searching of spatial data, human-computer images interaction technology based on remote sensing data developed and got attention. 1980s was a landmark period 
for GIS, during which GIS continued to mature as the popularity of computer and was known better, and a multitude of commercial GIS soft-wares came to the fore, such as ARC/INFO GIS released by ESRI company with good user interface and multiple data interface and secondary development function [5]. Since the 1990s, GIS as a new high-tech was widely employed and turned into an important component of information industry and one of fastest growing fields. With the development of information technique, GIS is known as more as possible, and penetrate into every field, and become essential working system for governments and other institutions [6].

\section{Application of GIS to Forestry}

As a completely new operation control instrument for forestry, GIS fundamentally changed traditional way of forestry source information management. In recent years, GIS has been used actively and popularly in dynamic changes of resources and environment, forestry resource management, comprehensive assessment, planning-decision service. In summary, applied research of GIS in forestry are as following: forest resource information management, forest operating optimized decision, forest classified management division, forestry sample design, forestry thematic mapping, forest cutting plan, afforestation planning programming, forest protection, forest resource administration net GIS, precision forestry [7].

\section{Forest Resource Information Management}

Foreign countries set an early foot in using GIS to manage forest resource information, for example, Canada started in the nation-wide in 1980s [8]. However, in our country, it is being carried out. More and more scholars pay attention to the research on integrating GIS and forest resource management organically as following: forest resource archives management, forestry land use change monitoring, forest resource dynamic monitoring and management, forest ownership management.

Forest resource geographic information management is different from its resource information, which analyze spatial data as vital information and attribute data comprehensively, overcoming defects of single data, things such as WIN GIS [9]. Our country has developed kinds of types of forest resource geographic information system at several scales based on GIS. All of systems of province, country, tree farm, village play an important role in forest resource management.

Provincial system makes geographic information system be subordinated into a monitoring one, which improve space surveillance and management capacity of forest resource [10]. GIS designed for forestry production management by $\mathrm{Fu}$-hai $\mathrm{Li}$ independently, on the basis of requirements of modern resource management and forest operating, has practicability, pertinence, and scalability [11].

Country forestry resource researching data can be took full advantage to sets up corresponding geographic information system, offering an effective tool to monitor and operate forestry resource dynamically for competent authorities. Under the support of View GIS, Sheng-li Ma established a forestry resource geographic information system of the town in Shan-xi province [12]. Some created a system which can administrate and update data using GIS, remote sensing(RS) and mathematical model technology. Under the required fame of forestry resource information management all over the country, Others utilize Arc-object and COM technology to build country-level systems, as Shi-lin set up a platform to manage, monitor, and analyze forestry resource based on wavelet scale, applying ESRI of Map Objects combined RS, data-driven, prediction model of forest growth technology [13]. Component GIS, of which function module and distributed advantages can make MIS and GIS becoming combined well to meet the requirements in practice, gives new energy and power and the system, and what's more, brings new ideas and ways to system construction [14].

To develop GIS of forest resource can improve using effect of forest resource inventory data for management, providing technology support for grasping forest resource trends and scientific management, namely using OLE automation or component techniques to develop GIS (Map Info, Arc-view) and visualization tools integratedly [15]. 
It is a beneficial attempt to create village GIS to make the application more universal. Yuan Zhang took advantage of View GIS to establish the forestry resource information management system of a country in Liao ning Province, which made thematic maps, statistical analysis of categorical data, three-dimensional topography exhibition and digitization management of forestry resource come true [16].

In conclusion, there are four types of forestry resource GIS as following: one is to stand-alone development, proceeding completely from basement while not relying on any GIS, with disadvantage of great difficulty, long cycle, large investment; one is to make use of GIS software tools to machine and manage data with complete functions and poor pertinence; one is to utilize secondary development language on the basis of GIS to develop application-specific system of forestry information manage having the characteristics of simple model and bad portability; the last is component GIS of which controls can be embedded into user application program, easily to be transplanted, maintained, combined with special model organically.

\section{Forest Operating Optimized Decision}

To carry out qualitative analysis of optimal management and auxiliary model of forestry can provide more accurate information to inspect scientific and practical operating scheme as to satisfy the demands in management. Duan-lv Chen combined organically GIS with optimal decision model and analyzed both spatial and attribute data, which could display achievements in the form of visualization, and provide technical support for operation transformation from extensive form to intensive one [17]. Xiao-li Zhang, based on GIS and plenty of precise and reliable spatial database, displayed the results visually of multiple objects optimization and decision making, offering timing, locating, quantitative information, and achieving better results[18].

\section{Forest Classified Management Division}

Jun Hong applied GIS to distinguish the the forestry via function group in survey region, and showed visual results which can be stored, inputted only once and invoked more than once, overcoming the shortcomings of obvious subjective orientation in regional forest layout, that is to say that GIS spatial analysis methods can make forestry play its own leading functioning to realize automation, visualization, as well as imaging [19].

\section{Forestry sample design}

Sampling is the element working used widespread in forest survey. The transitional method is to utilize random figures to locate points firstly on maps, images, forest thematic pictures, then set out to relevant position on the spot by coordinate method. Huan-liang Wang expended professional sample design function of forest in GIS, adopting Map Basic programming language to implement three visualization layout of sampling points, and inquire and print arbitrarily sampling points distribution diagram and their detailed drawing of site[20].

\section{Forestry Thematic Mapping}

Forestry Map signifies its appearance to guide its management measures to be practicable, which is important for working out management projects and integrated design, being widely used to analyze, forecast, plan and design, and administrate, and being of great importance in intensive farming. Fu-xiao Gong adopted GIS to set up corresponding digitized forestry thematic mapping, showing that GIS can form dynamic images and combine resource monitoring with high yield cultivation measures as to make scientific scheme of operating decision [21]. At present, most of researchers make digitized forestry thematic mapping established by GIS (Map info, ARC/Info, Map GIS, View GIS), 
for instance, Xue-feng Wei used component technology MAP X to construct the maps and obtained better results [22].

\section{Forest Cutting Plan Management}

GIS can make cutting quota index released and digitized maps combined well. Spatial analysis intuitively on forestry cut is to make allocated quantity put into wavelet, which can be reflected in specific region space thus giving an index to kinds of different geographic spatial distribution of the style and amount of cut. GIS could analyze the correlations among related geographic property, the rationality of cut in space, the influence of cut process and spatial arrangement on the conservation of biological diversity. FORES TAR developed by Guo-fan Shao based on GIS has been well applied on cut plan and management [23].

\section{Afforestation Planning Programming.}

GIS applied on afforestation planning programming can know forestry resource and biological diversity more accurately, and make decision on production and business more effectively. Afforestation planning archives could be administrated by GIS to generate dynamically the afforestation scatter-gram in locate area, offering visualization method for matching species and varieties to the site. Some scholars attempt to use Map GIS to design afforestation program in order to make positive contribution to schedule control and ecological environment construction[24]. Huai-qing Zhang exploited spatial analysis function of GIS to assess farmland site and select planting species, in which slope and its aspect, soil types, and altitude were regarded as factors in order to improve visual degree [25].

\section{Forest Protection}

\section{GIS Applied to Fire Management.}

It is often to break out fire, one of core reasons that vastly destroy forestry, which poses great threat to human life and property, earth's resource, biological environment. Recently with global warming, forestry fire has increased. Each country all applies high-tech to strengthen fire management which have important implications for protecting forestry. GIS is used in forestry fire administration at home and abroad focusing primarily on aided design, prediction, detection and save, damage assessment and so on.

Jin-ping Gao developed forestry fire prevention aided decision system based on COM, which assists the department in making scientific decision to put out fire via fire tendency simulation, loss estimation, as well as optimum route analysis, embodying fully client/server, spatial database management, and COM technologies that realize multiple-user real-time operating, mass geographic data administration to make advanced information technology serve fireproofing [26]. With in-depth technique application, the systems would inspire potential more and more, as GIS and WEB technology applied on fire forecast have became a research focus. Hao-ruo Yi pointed out that it was of great importance of fireproof and protection to establish the fire danger prediction system on the network and GIS platform where information could be delivered in time so as to meet timeliness[27]. Other scholars pay attention to com-positive application of GIS, RS and GPS in this field. Gui Zhang proposed to set up forestry fire prevention system over Guang zhou on account of RS, GIS, GPS and electronic technique, which could all-weather monitor fire, predict behavior, offer remote and real-time image information on the site thus making scientific decision[28]. It is also the key trend to prevent fire at present. 


\section{GIS Applied to Forestry Pest Control.}

It is quite essential to manage large quantity space data related to forestry pest using database function of GIS, because pest have clear characteristic of spatial position while traditional methods can't analyze spatially; simultaneously prediction, evaluation, decision support require a large mount of spatial data and manipulation [29]. GIS is just exactly an advanced technology being suitable to managing and dealing with spatial data. It is a new hot spot to utilize spatial analysis technique of GIS to forecast forestry pest control. According to pest regularity of outbreak, and the relationship among environmental ecological factors combined with expert base, it is feasible to build pest prediction model and assess damage loss and determine its distribution diagram. Decision support based on GIS is mainly to formulate pest treatment measure and identify the critical path to the disaster area, making disaster control and assessment more scientific and accurate, which would has extensive application prospects.

\section{Forest Resource Administration Net GIS}

Web GIS is defined as GIS on the net, namely a new technology using internet and WWW technology to perfect and extend conventional geographic information system function, conveniently retrieving needed data and analyzing spatially. GIS also matches digitized forestry and information society. Xu Zhang did some research on sharing technology and setting an example in allusion to forestry resource information, and activated net sharing system framework, providing a good reference [30]. Guang-qiang Xiao came up with a publishing system on the basis of vector data using Arc IMS and Map Objects Java Edition with secondary development by ESRI, which adopted B/S structure with cross-platform and scalability [31]. Rui-lan Wang developed a net geological information system based on Arc GIS to show, inquire, count up forestry resource stocks, which was easy to analyze and simple to be used [32]. Compared Web GIS with the old, the former has advantage of strong adaptation, wider application, better present situation, maintenance socialization, ordinary usability. However, Web is just a start, and there is still a lot of work to be done.

\section{GIS Applied to Precision Forestry}

Precision Forestry means a modern forestry technical system of integration, intelligence, digitization, established by high technology as more as possible, with the purpose to make forestry exert ecological, economical, and social benefit and to realize sustainable operation and development [33]. In our country, it is just the beginning, namely still at the academic research and experiment stage of some technical links. GIS is one of the key techniques, offering basic platform for integrated system, which would be widely used in the future.

\section{GIS Applied to Other Aspects}

GIS should be really the basis of digitized forestry, of which connotation lie primary in two aspects: one is digitized forestry information on the foundation of GIS, RS, and GPS ("3S"); one is to store, analyze, process, and apply digital information; all of which owes to the comprehensive analysis and integrated function of GIS [34]. Therefore, digitized forestry not only express all characteristics in digital form, but also synthetically apply related information.

GIS can also build digital elevation model (DEM), through which topographical factors can be extracted automatically instead of partial field inspection, with advantage of speediness, science, and subjective [35]. At the same time, vegetation distribution can be known via thematic mapping in favor of resource environment management and ecological protection.

What's more, GIS play a significant role in wildlife administration, forest ecology, forestry project, biodiversity protection, and forest construction [36]. As an effective tool to deal with spatial ubiety, GIS could be beneficial to solve lots of forest problems decided by its own features.

\section{Conclusions and Prospects}

GIS, as a management tool and advanced technology in mint condition, is spilling over into forest in various fields and will do, on the grounds that the development of contemporary natural science and computer technique are changing business and administration pattern, which could not only settle many of the issues inextricable in traditional methods, but also explore new laws. One of the sally ports to the new scientific and technological revolution is how to make a breakthrough in bond 
between forestry resource and information technique, such as " $3 \mathrm{~S}$ " having made considerable progress and wide application to resource investigation, monitoring, and image processing. In future GIS would be more developed and applied in forest in these aspects as following: the stable and fleet system of data acquisition and updating, spatial data quality and its uncertainty analysis, data sharing and standard, three-dimensional GIS, organic bond of professional component model (resource renewal and growth model) and GIS, dynamic integration among "3S", object-oriented spatial database, and so on.

\section{References}

[1] Shu-peng Chen. Introduction to Geographic Information System. (Science Press,Beijing 2002). (In Chinese).

[2] Mitchell S, Csillag F, Tague, C: submitted to In Proceedings of the Open Source GIS-GRASS Users Conference. Trento, Italy, (2002), 11-13.

[3] Abadi D J. : Data Engineering. (2009), 3-8.

[4] Aboulnaga A, Salem K, Soror A et al.: Data Engineering. Vol. 32-1 (2009), 13-18.

[5] David M. Stoms, Jennifer M. McDonald, Fuzzy: Environmental Management. Vol. 29-4 (2002), 545-558.

[6] Chao Zhang.Geographic Information System.(High Education Press,Beijing 2000).(In Chinese).

[7] Rebolj D, Sturm PJ. Sturm: Environmental Modeling and Software. Vol. 32-1 (1999), Vol. 14-6: 531-539.

[8] Korkalainen T , Laurén A: Geomorphology. Vol. 74-1 (2006), 271-284.

[9] D.A. Hughes , D.A. Forsyth: Computers \& Geo-sciences. Vol. $32-9$ (2006), 1389-1402.

[10] Anne C.S. McIntosh, Judith B: Ecological Information, Vol. 2-3 (2007), 224-236.

[11] Fu-hai Li: Henan Forestry Science and Technology. Vol. 3 (2002), 14-16. (In Chinese).

[12] Sheng-li Ma: Shanxi Forestry Science and Technology. Vol. 1 (2002), 36-39. (In Chinese).

[13] Chao-zong Xia: Journal of Beijing Forestry University. Vol. 26-3(2004), 24-28. (In Chinese).

[14] M. St-Vincent, D. Denis, D. Imbeau, R. Trudeau: International Journal of Industrial Ergonomics. Vol. 36-4(2006), 313-321.

[15] Heng Lv, Shi-kui Peng: Journal of Nanjing Forestry University (Natural Science Edition). Vol. 27-6(2003), 67-71. (In Chinese).

[16] Yuan Zhang: Central South Forest Inventory and Planning. Vol. 2 (2004), 49-52. (In Chinese).

[17] Duan-lv Chen, Wan-qing Chen: Central South Forest Inventory and Planning. Vol. 21-03 (2002) (2002), 44-47. (In Chinese).

[18] Xiao-li Zhang. Journal of Beijing Forestry University. Vol. 25-S1(2004), 77-82. (In Chinese).

[19] Jun Hong. Journal of Northeast Forestry University. Vol. 30-4(2002), 14-18. (In Chinese).

[20] Huan-liang Wang. Journal of Surveying and Mapping Engineering. Vol. 12-4(2004), 30-32. (In Chinese).

[21] Fu-xiao Gong: Gansu Forestry Science and Technology. Vol. 28-1 (2003), 74-75. (In Chinese). 
[22] Xue-feng Wei: Forest Inventory and Planning. Vol. 28-3 (2003), 67-70. (In Chinese).

[23] Guo-fan Shao: Journal of Forestry Research. Vol. 14-2 (2003), 141-145. (In Chinese).

[24] Satyanarayana B, Raman A V. : Journal of Nanjing Forestry University (Natural Sciences Editions), Vol. 4 (2004), 13-18.

[25] Huai-qing Zhang: Forestry Science Research. Vol. 14-2 (2003), 141-145. (In Chinese).

[26] Jin-ping Gao: Forestry Resources Management. Vol. 2 (2003), 54-57. (In Chinese).

[27] Hao-ruo Yi: Forestry Science. Vol. 40-3 (2004), 203-207. (In Chinese).

[28] Gui Zhang: Central South Forestry University. Vol. 24-2 (2004), 94-99. (In Chinese).

[29] An-xing Liu: Journal of Nanjing Forestry University . Vol. 30-2(2006), 127-130. (In Chinese).

[30] Xu Zhang: Resource Science. Vol. 23-1(2001), 54-59. (In Chinese).

[31] Guang-qiang Xiao: Forestry Resources Management. Vol. 4 (2001), 70-72. (In Chinese).

[32] Rui-lan Wang: Forestry Resources Management. Vol. 3 (2004), 63-65. (In Chinese).

[33] Yu-zao Nie: Journal of Beijing Forestry University. Vol. 24-3 (2002), 89-92. (In Chinese).

[34] Matheron G. : Economic Geology. Vol. 58 (2010), 1246-1266.

[35] Tu-sheng Li: Journal of Nanjing Forestry University (Natural Science Edition). Vol. 26-5(2002), 53-56. (In Chinese).

[36] Stevens D L Jr., Olsen A R. : Environmetrics. Vol. 14 (2003), 593-610. 